\title{
Comparing face-to-face intubation with different devices
}

\author{
Jia-Qiang Zhang ${ }^{1}$ Fu-Shan Xue ${ }^{2}$ Fan-Min Meng ${ }^{1}$
}

Received: 17 February 2016 / Accepted: 20 February 2016 / Published online: 4 March 2016

(C) Japanese Society of Anesthesiologists 2016

\section{To the Editor:}

In the recent report by Arslan et al. [1] comparing faceto-face intubation using Airtraq, Glidescope and Fastrach devices in adult patients, we believe there are design limitations that make interpretation of their findings questionable. The aim of their study was to evaluate the performance of three devices for emergency intubation in a prehospital environment; however, it was conducted in a controlled environment, i.e., intubation was performed in anesthetized, paralyzed patients lying on an operating table under room light. In an actual prehospital situation, emergency intubation is often required to be conducted in patients lying on the ground in direct daylight. A common flaw of videolaryngoscopes, including Airtraq and Glidescope, is that reflection of the sunlight on the video monitors may make it difficult to see the glottis in daylight [2]. Moreover, the height of the operating table can affect the performance of laryngoscopic intubation. In addition, comparing intubation times with three devices is not entirely appropriate. The ventilatory capacity of the Fastrach device is arguably equally important to its effectiveness as an intubation conduit during airway resuscitation. If intubation via the Fastrach device fails, the presence of an effective airway can evidently be lifesaving.

Finally, in Table 2, the total number of patients requiring different attempts in the Glidescope and Fastrach groups is more than the actual sample sizes.

\section{Compliance with ethical standards}

Conflict of interest All authors have no financial support and potential conflicts of interest for this work.

\section{References}

1. Arslan ZI, Alparslan V, Ozdal P, Toker K, Solak M. Face-toface tracheal intubation in adult patients: a comparison of the Airtraq $^{\mathrm{TM}}$, Glidescope ${ }^{\mathrm{TM}}$ and Fastrach ${ }^{\mathrm{TM}}$ devices. J Anesth. 2015;29:893-8.

2. Ueshima $\mathrm{H}$, Asai T. Tracheal intubation in daylight and in the dark: a randomised comparison of the Airway Scope, Airtraq, and Macintosh laryngoscope in a manikin. Anaesthesia. 2010;65:684-7.
Fu-Shan Xue

xuefushan@aliyun.com

1 Department of Anesthesiology, Henan Provincial People's Hospital of Zhengzhou University, Zhengzhou, People's Republic of China

2 Department of Anesthesiology, Plastic Surgery Hospital, Chinese Academy of Medical Sciences and Peking Union Medical College, 33 Ba-Da-Chu Road, Shi-Jing-Shan District, Beijing 100144, People's Republic of China 